\title{
Effects of LED light quality on the growth of pepper seedling in plant factory
}

\author{
Nan Liu, Fang Jï, Lijun Xu, Dongxian He \\ (Key Lab. Agricultural Engineering in Structure and Environment of Ministry of Agriculture and Rural Affairs, \\ College of Water Resources \& Civil Engineering, China Agricultural University, Beijing 100083, China)
}

\begin{abstract}
The extensive environment, especially low temperature and weak lighting in winter and spring, which limits the growth of pepper (Capicum annuum L.) seedlings, the use of plant factory with artificial lighting technology can effectively control the lighting environment to produce high-quality seedlings. In this study, white LED lamps with R:B ratio of 0.7 (L0.7) and 1.5 (L1.5) and red-blue LED lamps with R:B ratio of 3.5 (L3.5) were used to cultivate seedlings of "CAU-24" pepper in the light intensity of $250 \mu \mathrm{mol} / \mathrm{m}^{2} \cdot \mathrm{s}$ and photoperiod of $12 \mathrm{~h} / \mathrm{d}$, white fluorescent lamps with R:B ratio of 1.7 (F1.7) was used as control. The results showed that plant height, stem diameter, hypocotyl length, biomass accumulation, light energy use efficiency (LUE) and electric energy use efficiency (EUE) of pepper seedling under L1.5 were the highest. After 36 days of sowing, the dry weight of shoot reached $302.8 \pm 45.2 \mathrm{mg} /$ plant. Leaf area reached maximum value of $153.5 \pm 22.0 \mathrm{~cm}^{2}$ under L0.7. The contents of chlorophyll $a$, chlorophyll $b$ and total chlorophyll of pepper seedling leaves under all kinds of LED light were greater than F1.7, but there was no significant difference in net photosynthetic rate. The total dry weight with lamp electric power consumption of L1.5 were $3.0 \mathrm{~g} /(\mathrm{kW} \cdot \mathrm{h})$ which was $1.5,2$, and 3 times greater than that of L3.5, L0.7, and F1.7, respectively. Therefore, compared with fluorescent lamp and other LED lamps, the white LED light quality with R:B ratio of 1.5 is suitable for pepper seedling production in plant factory because of the high LED lighting efficiency, greater LUE and EUE. Keywords: pepper seedlings, LED light quality, R: B ratio, light energy use efficiency (LUE), electric energy use efficiency (EUE)

DOI: $10.25165 /$ j.ijabe.20191205.4847
\end{abstract}

Citation: Liu N, Ji F, Xu L J, He D X. Effects of LED light quality on the growth of pepper seedling in plant factory. Int J Agric \& Biol Eng, 2019; 12(5): 44-50.

\section{Introduction}

With the increasing production area of greenhouse vegetable in China, the annual demand for seedlings is also increasing, reaching 680 billion in 2015. According to FAO statistics, pepper production in China reached $35000 \mathrm{t}$ in 2017, accounting for about $5 \%$ of the world's pepper production. However, in off-season cultivation, current greenhouse seedling often encounters low temperature and weak lighting, which limits the seedlings growth, resulting in a decline in the quality and yield. The plant factory with artificial lighting (PFAL) can create a suitable environment for vegetable seedling breeding, so that the seedlings growth in the system will be not or less restricted by natural environmental conditions, and the seedlings growth cycle in the system will be short and less polluted, which combined with multi-shelves cultivation throughout the year, will double or even tens of times the utilization rate of land per unit area and the yield of seedlings ${ }^{[1,2]}$. However, although the PFAL has solved many problems existing in industrialized nursery process, high initial

\section{Received date: 2019-04-25 Accepted date: 2019-08-27}

Biographies: Nan Liu, Master Candidate, research interest: plant factory technology, Email: 460292508@qq.com; Lijun Xu, Master, research interest: plant factory technology, Email: 1048765506@qq.com; Dongxian He, Professor, research interests: plant environmental physiology and plant factory technology. Email: hedx@cau.edu.cn.

*Corresponding author: Fang Ji, PhD, Lecturer, research interest: plant environmental physiology. Key Lab. Agricultural Engineering in Structure and Environment of Ministry of Agriculture and Rural Affairs, College of Water Resources \& Civil Engineering, China Agricultural University, Beijing 100083, China. Tel: +86-10-62737550, Email: jifang@cau.edu.cn. construction cost, high actual operation cost and high energy consumption are still the bottlenecks hindering its application and promotion. For example, the amount of electricity consumed by artificial lighting in this technology accounts for more than $80 \%$ of the total power consumed in all production process of the PFAL ${ }^{[3]}$. In order to reduce the electricity cost of PFAL, it is necessary to improve the electric energy use efficiency (EUE) and light energy use efficiency (LUE) of the plant factory system ${ }^{[4]}$.

The energy required for plant growth, development and morphogenesis is mainly supplied by light, and the expression of related plant genes is regulated by the signal and energy effects of light, so as to complete the physiological behavior of vegetative growth and reproductive growth of plants ${ }^{[5]}$. In solar radiation, only visible light is effective for plant photosynthesis, and visible light of different wavelengths has significant effects on plant physiological activities. The results showed that in the visible spectrum range of $380-760 \mathrm{~nm}$, photosynthesis absorbs about $60 \%-65 \%$ of the physiological radiation energy, and the absorption peaks are mainly red-orange light with $610-720 \mathrm{~nm}$ wavelength and blue-violet light with $400-510 \mathrm{~nm}$ wavelength ${ }^{[6]}$. Light-emitting diode (LED) is a new type of semiconductor light source, and the wavelength of its light depends on the characteristics of semiconductor materials. The peak wavelength of light emitted by LED can be from UV-C $(\sim 250 \mathrm{~nm})$ to infrared $(\sim 1000 \mathrm{~nm})^{[7]}$. In addition, LED is the first light source with controllable spectrum. By controlling its spectra, the LED light wavelength can be matched with plant photoreceptors, so as to better improve the yield and quality of plants ${ }^{[8]}$.

In the past, greenhouse plant cultivation was often limited by light sources, because traditional commercial light sources could 
not provide high-level and stable photosynthetic photon flux and effective radiation energy similar to the solar spectrum. In the late 1980s, the United States has tried to use LED as a light source for plant growth ${ }^{[9]}$. In 1995, Brown et al. ${ }^{[10]}$ used metal halide lamp, red LED, red supplemented with far-red LED, and red LEDs supplemented with blue light from blue fluorescent lamp when planting pepper, and it was found that pepper biomass under metal halogen lamp was the highest, followed by those under red-blue LED. Compared with traditional artificial light source, mercury does not need to be treated in the production of LED, and the materials of cold light source can be used to irradiate plants at close range, with long service life and more prominent energy saving. In addition, the LED lamp has a long service life and is more energy-saving ${ }^{[8]}$. Ricardo et al. ${ }^{[11]}$ found that the biomass accumulation, leaf area and chlorophyll content of tomatoes under red plus blue LED were greater than those under monochrome red or blue LED, and the growth efficiency of tomatoes under R:B of 2.3 was $172 \%$ greater than that under cold-white fluorescent lamp. Cao et al. ${ }^{[12]}$ found that red plus blue light was beneficial to the growth of cucumber seedlings, and the plant height, dry matter quality and $\mathrm{Fv} / \mathrm{Fm}$ were significantly increased compared with those of control group treated with single red or blue light treatment. Song et al. ${ }^{[13]}$ found that white LED is more suitable for producing high quality cucumber seedlings than the lack of green light and/or high R:B ratio provided by the red plus blue light. Futhermore, the research of Ohashi et al. ${ }^{[14]}$ showed that changing light quality in PFAL could improve the yield and nutritional value of lettuce, spinach and komatsuna.

Thus, it is apparent that various LED light qualities can have a significant impact on plant growth and morphogenesis. However, there are few researchers examined the effect of light environment on pepper seedlings. Therefore, the objective of this study was to investigate the effects of different LED light quality on the growth of pepper seedlings in PFAL.

\section{Materials and methods}

\subsection{Plant materials and growth conditions}

Pepper seeds (Capicum annuum L. cv. CAU-24) were seeded in a 105 cell plug trays $(540 \mathrm{~mm} \times 280 \mathrm{~mm})$ containing $60 \%$ vermiculite, $20 \%$ peat, and $20 \%$ pearlite. After sowing, the seeds were directly placed in the growth chamber (China Agricultural University, Beijing, China) for $4 \mathrm{~d}$. During the period of germination, the environment was set as follows: the temperature was $28^{\circ} \mathrm{C} \pm 1{ }^{\circ} \mathrm{C}$ in the photo period and $22^{\circ} \mathrm{C} \pm 1{ }^{\circ} \mathrm{C}$ in the dark period, the relative humidity was set as $80 \% \pm 10 \%$ and $\mathrm{CO}_{2}$ was not controlled. On the third day, the substrate was irrigated with clear water by bottom irrigation. The pepper seeds germinated on the 8th day after sowing and were treated in different lighting environments, while the growth measurement was carried out on the 36th day after sowing. The environment of seedling-raising stage was set as follows: the temperature was $24^{\circ} \mathrm{C} \pm 1^{\circ} \mathrm{C}$ in the photo period and $20^{\circ} \mathrm{C} \pm 1{ }^{\circ} \mathrm{C}$ in the dark period, the relative humidity was $70 \% \pm 5 \%$ in the photo period and $80 \% \pm 10 \%$ in the dark period, and the concentration of $\mathrm{CO}_{2}$ was $400 \pm 50 \mu \mathrm{mol} / \mathrm{mol}$.

After germination, pepper seeds began to be watered with nutrient solution, which was formulated with Japanese garden type formla (major element with mol/L in $\mathrm{N}$ : $\mathrm{P}: \mathrm{K}: \mathrm{Ca}: \mathrm{Mg}=16: 4: 8: 8$ : 4; miacro element with $\mathrm{mol} / \mathrm{L}$ in Fe: B: $\mathrm{Mn}: \mathrm{Zn}: \mathrm{Cu}: \mathrm{Mo}=3: 0.5$ : $0.5: 0.05: 0.02: 0.01$ ). During the period from seed germination to the one true leaf stage, the seedlings were irrigated with $1 / 2$ concentration of nutrient solution every two days by bottom irrigation. After the one true leaf stage, the seedlings were irrigated with standard concentration of nutrient solution with $\mathrm{pH}$ of 6.8-7.2and EC of 2.0-2.4 mS/cm. The duration of absorption of nutrient solution by substrate was more than $30 \mathrm{~min}$ during bottom irrigation.

\subsection{Treatment design}

In the light quality experiment of pepper seedlings, four different light treatments were provided by white LED lamps with R:B ratio of 0.7 (L0.7) and 1.5 (L1.5) (Shenzhen Changtian Environmental Protection Co., Ltd., China., Tianjin Jinya Electronics Co., Ltd., China), red plus blue LED with R:B ratio of 3.5 (L3.5) (Panasonic Electrical Appliances (China) Co., Ltd., China), and white fluorescent lamp with R:B ratio of 1.7 (F1.7) (Shanghai Flower and Biology Lighting Co., Ltd., China). Among them, the F1.7 was the control group, and each light quality treatment device was placed on a random layer on a designated shelf to avoid light pollution from adjacent treatment devices (Figure 1). The light environment treatments mentioned above were controlled by a web-server embedded environmental control system, and the photoperiod was $12 \mathrm{~h} / \mathrm{d}$. In the experiment, the spectral distribution of $300 \mathrm{~nm}$ to $800 \mathrm{~nm}$ wavelength at $15 \mathrm{~cm}$ below the lamp was measured by a fiber spectrometer (AvaField-1-Dual, Avates Inc., Netherland). In all light environment treatments, the light intensity was about $250 \mu \mathrm{mol} / \mathrm{m}^{2} \cdot \mathrm{s}$. According to the spectral distribution, the photon fluxes of blue light (B, 400-499 nm), green light ( $\mathrm{G}, 500-599 \mathrm{~nm})$ and red light ( $\mathrm{R}$, $600-700 \mathrm{~nm}$ ) were calculated, and the R:B ratio were calculated by the photon fluxes of red and blue light wavelength.

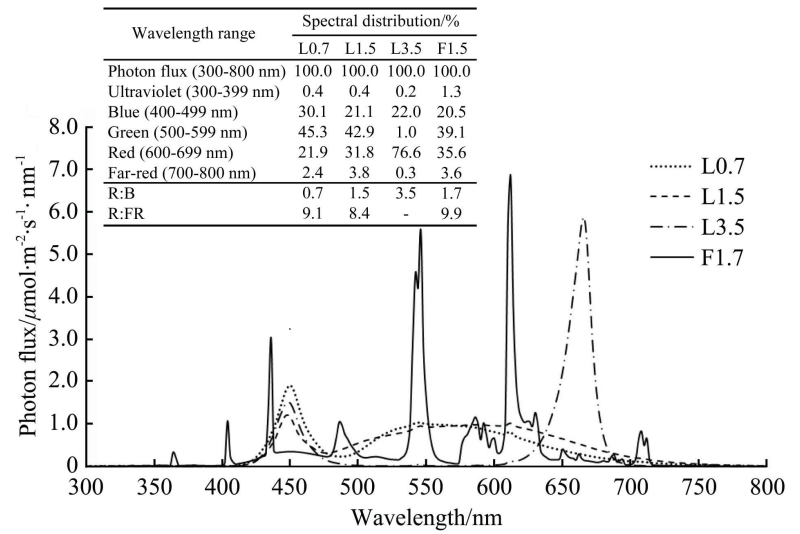

Figure 1 Spectral distribution of fluorescent lamp with R:B ratio of 1.7 (F1.7) and three LED lamps with R:B ratio of 0.5, 1.7 and 3.5(L0.5, L1.7 and L3.5), respectively

\subsection{Growth measurements}

\subsubsection{Plant morphology and growth characteristics}

On the 36th day after sowing, eight seedlings were randomly selected to measure their plant height from the media surface to the meristem tip with a steel tape ruler in $\mathrm{cm}$, the middle part of hypocotyl and cotyledon of seedling were selected to measure stem diameter with an electronic vernier caliper (573-605/705, Japan Sanfeng Measuring Tools Precision Co., Ltd) in mm, and each blade was scanned by a scanner (LiDE 110, Canon (China) Co., Ltd.) for calculating the leaf area through image processing. Finally, the above-ground and underground parts were placed in an oven at $105^{\circ} \mathrm{C}$ for $3 \mathrm{~h}$, then the oven temperature was adjusted to $80^{\circ} \mathrm{C}$ and the plant was dried for $72 \mathrm{~h}$. After cooling to room temperature, the dry weight of each plant was weighed and recorded with one-thousandth electronic balance (FA1204B 
Electronic Balance, Shanghai Precision Scientific Instruments Co., Ltd., China) in mg.

\subsubsection{Chlorophyll content measurement}

The second completely unfolded true leaf on each seedling was taken as a sample, and its chlorophyll content was determined by UV/VIS spectrophotometer (UV-3150, Shimadzu Co., Japan) and calculated by revised Arnon method ${ }^{[15]}$. The absorbance of chlorophyll was measured at $663 \mathrm{~nm}$ and $645 \mathrm{~nm}$, respectively.

\subsubsection{Photosynthetic characteristics}

Photosynthetic characteristics of pepper seedlings were measured by a portable photosynthetic system (LI-6400, LI-COR Inc., USA). The parameters of photosynthesis measurement were set as follows: air flow rate was $500 \mu \mathrm{mol} / \mathrm{s}$, the PPFD was $250 \mu \mathrm{mol} / \mathrm{m}^{2} \cdot \mathrm{s}$, the leaf chamber temperature was $25^{\circ} \mathrm{C}$ and the $\mathrm{CO}_{2}$ concentration was $400 \mu \mathrm{mol} / \mathrm{mol}$. There were 6 samples in each treatment, and the main indicators were net photosynthetic rate $\left(\mathrm{Pn}, \mu \mathrm{mol} / \mathrm{m}^{2} \cdot \mathrm{s}\right)$, stomatal conductance $\left(\mathrm{Gs}, \quad \mathrm{mol} / \mathrm{m}^{2} \cdot \mathrm{s}\right)$, intercellular $\mathrm{CO}_{2}$ concentration $(\mathrm{Ci}, \mu \mathrm{mol} / \mathrm{mol})$ and transpiration rate $\left(\mathrm{Tr}, \mathrm{mmol} / \mathrm{m}^{2} \cdot \mathrm{s}\right)$. The instantaneous water use efficiency was calculated by dividing net photosynthetic rate by transpiration rate $^{[16]}$

\subsubsection{Chlorophyll fluorescence parameters}

The chlorophyll fluorescence parameters of pepper seedlings were measured by the above portable photosynthesis system. The initial fluorescence yield $\left(F_{\mathrm{o}}\right)$ and the minimal fluorescence yield $\left(F_{\mathrm{m}}\right)$ were measured after dark adaptation for $2 \mathrm{~h}$. The chamber parameters were set as follows: the flow rate was $500 \mu \mathrm{mol} / \mathrm{s}$, the $\mathrm{CO}_{2}$ concentration was $400 \mu \mathrm{mol} / \mathrm{mol}$, the chamber temperature was $25^{\circ} \mathrm{C}$, and the PPFD of acting light was $800 \mu \mathrm{mol} / \mathrm{m}^{2} \cdot \mathrm{s}$. The maximal photochemical efficiency of PS II $\left(F_{\mathrm{v}} / F_{\mathrm{m}}\right)=\left(F_{\mathrm{m}}-F_{\mathrm{o}}\right) / F_{\mathrm{m}}$, the effective conversion efficiency of open PSII $\left(F_{\mathrm{v}}^{\prime} / F_{\mathrm{m}}{ }^{\prime}\right)=\left(F_{\mathrm{m}}{ }^{\prime}-\right.$ $\left.F_{\mathrm{o}}{ }^{\prime}\right) / F_{\mathrm{m}}{ }^{\prime}$, the photochemical quenching coefficient $\left(q_{\mathrm{P}}\right)=$ $\left(F_{\mathrm{m}}{ }^{\prime}-F_{\mathrm{s}}\right) /\left(F_{\mathrm{m}}{ }^{\prime}-F_{\mathrm{o}}{ }^{\prime}\right)$, the non-photochemical quenching coefficient $\left(q_{\mathrm{N}}\right)$ $=1-\left(F_{\mathrm{m}}{ }^{\prime}-F_{\mathrm{o}}{ }^{\prime}\right) /\left(F_{\mathrm{m}}-F_{\mathrm{o}}\right)$, the actual light transformation efficiency $\left(\Phi_{\mathrm{PS} \mathrm{II}}\right)=\left(F_{\mathrm{m}}{ }^{\prime}-F_{\mathrm{s}}\right) / F_{\mathrm{m}}{ }^{\prime}$, the non-photochemical quenching coefficient $(N P Q)=F_{\mathrm{m}}{ }^{\prime} / F_{\mathrm{m}}-1$ and the photosynthetic electron transport rate $(E T R)=\Phi_{\mathrm{PS} \mathrm{II}} \times P P F$ (the PPF of light measured) $\times 0.42$ were calculated by the above measured chlorophyll fluorescence parameters. Six samples randomly selected in each treatment.

\subsubsection{System energy efficiency accounting}

The power consumption of the light source was continuously monitored by a power monitor (T8006, Shenzhen BeiDian Instrument Co., Ltd., China). The LUE is the ratio of the increment of phytochemical energy per unit time to the total amount of light irradiated by light source. The EUE refers to the ratio of the increment of plant chemical energy to the total energy consumed by light source in a unit time (In this experiment, it refers to a cultivation period).

\subsection{Statistical analysis}

The processing and analysis of experimental data are completed with Microsoft Excel 2016 and SPSS 22.0, and the production of chart class is done with Microsoft Excel 2016. Duncan's method was used to make multiple comparisons at the significant level of 0.05 when using data statistical methods for significance and statistical analysis.

\section{Results and discussion}

\subsection{Effects of light quality on growth characteristics}

Different light quality had significant effects on plant height, stem diameter, leaf area, hypocotyl growth and biomass accumulation of seedlings (Figures 2 and 3). The plant height, stem diameter and hypocotyl length of pepper seedlings under L1.5 were significantly greater than the other three treatments, while the leaf area reached the maximum under L0.7, which was about $16 \%$ greater than that of F1.7. Different light quality can significantly affect the biomass accumulation of plants. Under L1.5, the dry weight of the shoot and root of the pepper seedlings were greater than the others, reaching $302.8 \pm 45.2 \mathrm{mg} /$ plant and $80.7 \pm 27.2$ $\mathrm{mg} /$ plant, which was about $40 \%$ and $33 \%$ greater than $\mathrm{F} 1.7$, respectively. That in the three LED light sources were similar or better than the white fluorescent lamps in terms of biomass accumulation.

Studies by Javanmardi et al. ${ }^{[17]}$ showed that tomato and pepper seedlings grown under full white light had the highest plant height, while growing alone under blue light along or in combination with red could reduce the height of tomato and pepper, which was similar to our research. Ricardo et al. ${ }^{[18]}$ set up different combinations of red plus blue LED and a consisted of $\mathrm{B}, \mathrm{G}$ and R LED to experiment on cucumber. They found that the hypocotyl of seedlings decreased with the increase of blue light proportion and reached the longest under single red light, which indicated that single blue light inhibited the elongation of hypocotyl, while single red light had the opposite effect. The leaf area, chlorophyll content and dry weight of cucumber seedlings increased with the increase of blue light proportion, but the addition of green light had no effect on the morphology of cucumber seedlings. Some studies showed that blue light receptor and phytochrome had different synergistic inter action with photosensitive pigments, which could inhibit stem elongation ${ }^{[19,20]}$. Otherwise, the hypocotyl elongation of Arabidopsis thaliana was also inhibited with the increase of blue light intensity ${ }^{[21]}$. However, when the red plus blue LED reached $210 \mu \mathrm{mol} / \mathrm{m}^{2} \cdot \mathrm{s}$, adding white light would balance the light environment, because white light could penetrate the plant canopy better than red plus blue light ${ }^{[22]}$, and red light and blue light had additive effects on extension of the leaves ${ }^{[23]}$. This study showed that the maximum leaf area under L0.7 was $153.5 \pm 22.0 \mathrm{~cm}^{2}, 63 \%$ more than that under L3.5, which might be due to the different separation mechanisms between blue and red light. Blue light and red light could increase the rate proton efflux of epidermal cells through separation mechanism, thus affecting the extension of the leaves. While the blue light directly stimulates proton pump through the direct interaction between the proton pump and blue light photoreceptor, while, the red light indirectly affected the proton pump through the modulating calcium and potassium channels of passive ion conductance $^{[24]}$. Similarly, Gomez et al. ${ }^{[25]}$ found that under LED with R:B ratio of 4 , tomato leaf area was nearly $13 \%$ larger than that under LED with R:B ratio of 19.

Ricardo et al. ${ }^{[11]}$ found that the dry weight of the shoot of tomato was greater under LED with R:B ratio of 2.33 and 1 than those under cold white fluorescent lamp, single red light and single blue light, but there was no significant difference between LED with $\mathrm{R}: \mathrm{B}$ ratio of 2.33 and 1 , respectively. Son et al. ${ }^{[26]}$ found that after four weeks of continuous irradiation to LED with R:B ratio of 9,4 and 1.5 , the dry weight of lettuce shoot and root reached the maximum under the LED with the ratio of 9 and the minimum under the LED with the ratio of 1.5, which indicated that the dry weights of lettuce shoot and root would increase with the increase of the ratio of R:B. However, in this study, it was found that the maximum dry weights of shoot and root were under the L1.5. 
Compared with L3.5, additional green light may promote plant growth. Kim et al. ${ }^{[27]}$ added green light to the red-blue LED to treat lettuce, and found that the dry weight of the shoot was greater
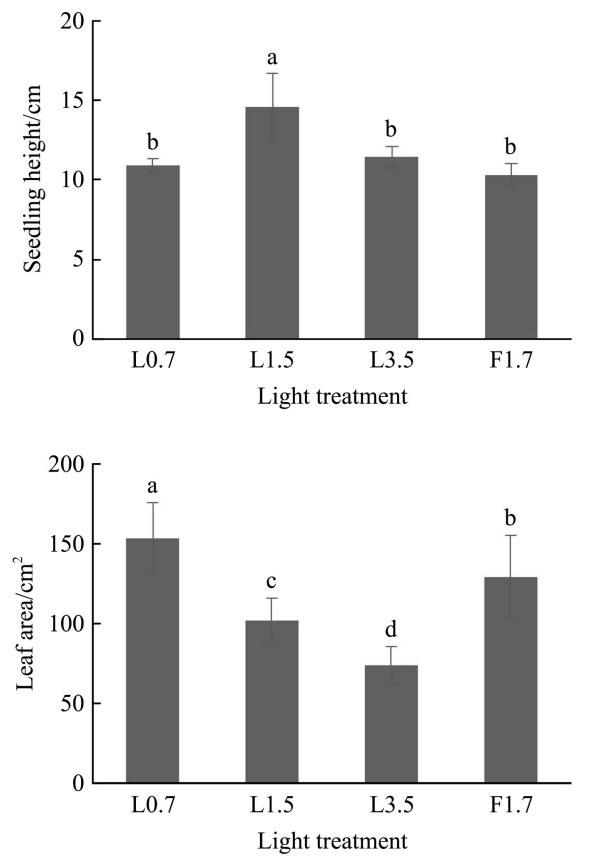

than that of the red plus blue treatment, because the leaves in the lower canopy could use the transmitted green light for photosynthesis.
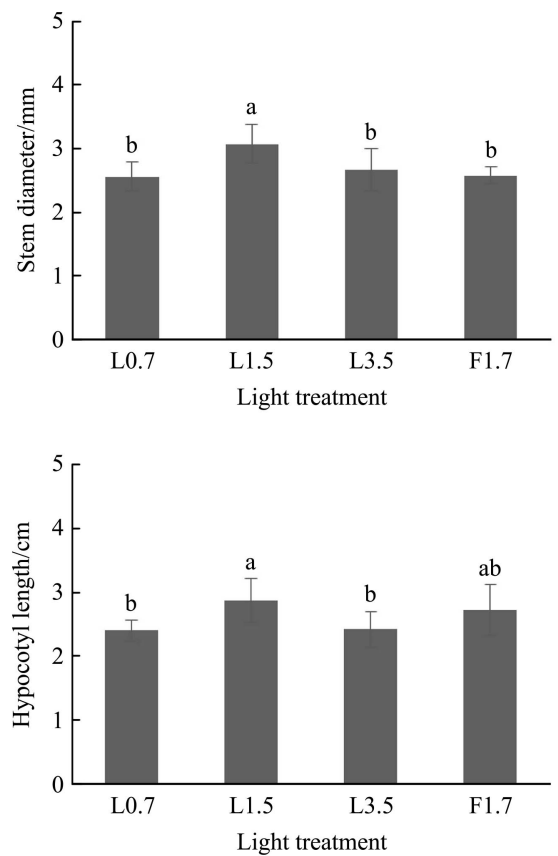

Note: Different letters in the same column indicate significant differences $(p<0.05)$ based on the Duncan's multiple range test. NS represent no significant difference at the 5\% level.

Figure 2 Effects of LED Light quality on the growth of pepper seedling
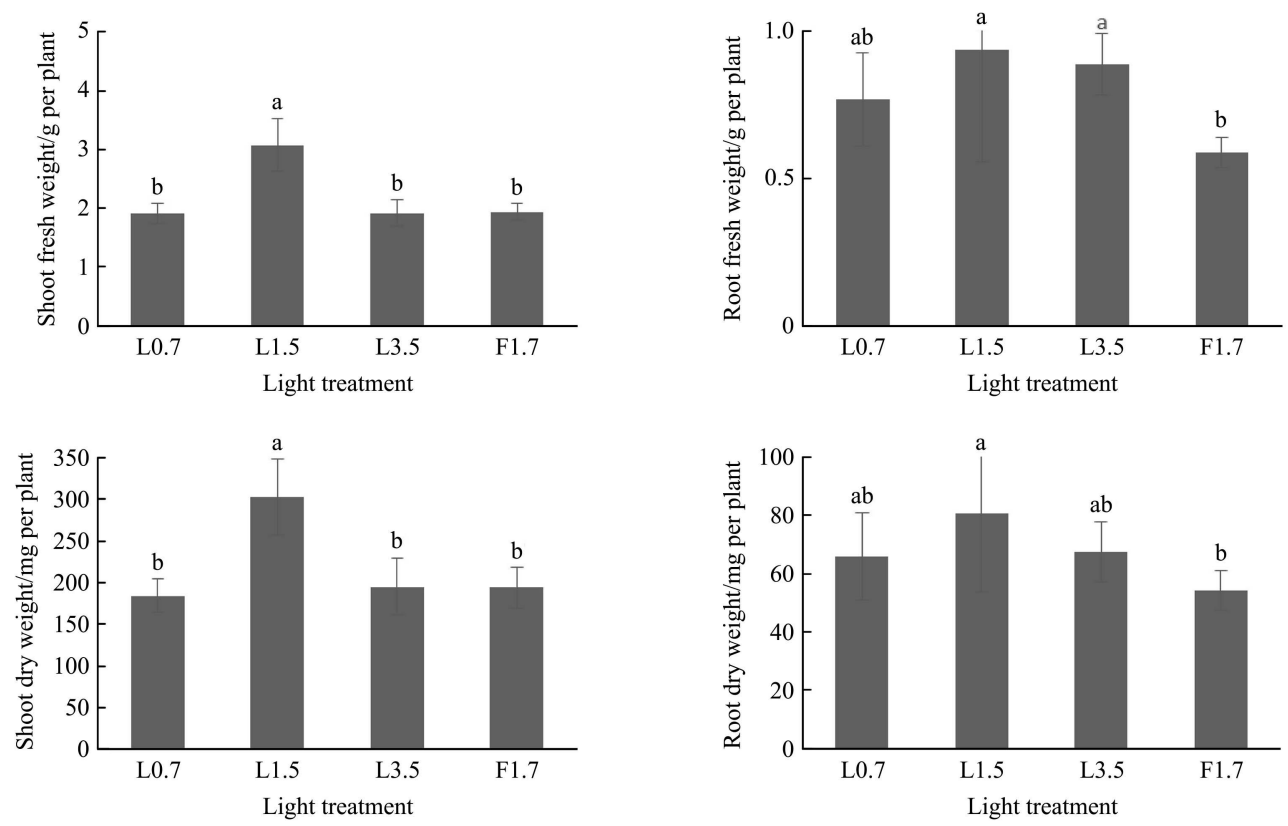

Note: Different letters in the same column indicate significant differences $(p<0.05)$ based on the Duncan's multiple range test. NS represent no significant difference at the $5 \%$ level.

Figure 3 Effects of LED Light quality on biomass accumulation of pepper seedling

\subsection{Effects of light quality on chlorophyll content}

Under L1.5, the chlorophyll a and total chlorophyll of pepper seedlings reached the maximum values, $1.73 \pm 0.14 \mathrm{mg} / \mathrm{g}$ and $2.34 \pm 0.21 \mathrm{mg} / \mathrm{g}$, while chlorophyll b was $0.61 \pm 0.08 \mathrm{mg} / \mathrm{g}$, slightly lower than that under L0.7. But there was no significant difference of chlorophyll $\mathrm{a} / \mathrm{b}$ between each other (Figure 4 ). The total chlorophyll content of plants under L3.5 was lower than that under F1.7, which was similar to other research results ${ }^{[28]}$, but the effect of light quality on chlorophyll depended largely on plant species. Craver et al. ${ }^{[29]}$ found that the total chlorophyll content of mustard under
LED with R:B of 6.7 was higher than that under blue plus green LED with B:G of 0.4 and red plus blue LED with extra far-red light ( $\mathrm{R}: \mathrm{B}=9.3$ ). Kpsell et al. ${ }^{[30]}$ found that the total chlorophyll content in broccoli increased with the increase of blue light percentage.

3.3 Effects of light quality on photosynthetic characteristics and chlorophyll fluorescence parameters

Light quality had a significant effect on the photosynthetic parameters of pepper, but there was no significant difference in net photosynthetic rate of pepper under different light quality. Intercellular $\mathrm{CO}_{2}$ concentration, stomatal conductance and 
transpiration rate were the greatest under L1.5 and F1.7, while the instantaneous water use efficiency under L0.7 was $7.6 \pm 1.6$ (Table 1), significantly higher than that under the others. The maximum $F_{\mathrm{v}} / F_{\mathrm{m}}$ of PSII in leaves was not found to be significantly different, and the values ranged from 0.75 to 0.85 (Table 2), indicating that different light quality treatments did not cause light stress on pepper seedlings under the light photoperiod of $12 \mathrm{~h} / \mathrm{d}$ and the light intensity of $250 \mu \mathrm{mol} / \mathrm{m}^{2} \cdot \mathrm{s} . \quad F_{\mathrm{v}}{ }^{\prime} / F_{\mathrm{m}}{ }^{\prime}$ represents the actual quantum efficiency of PSII during photoactivation, i.e. the quantum

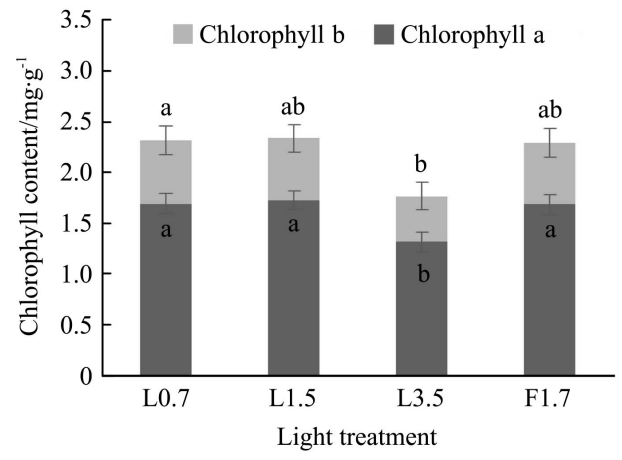

efficiency of charge separation in the reaction center of PSII, and there was no significant difference between different light qualities. There were no difference in the photochemical quenching coefficient $q_{\mathrm{P}}$ and the photosynthetic electron transport rate ETR, either. $\Phi_{\mathrm{PS} \text { II }}$ is the actual light transformation efficiency, and it is often used to represent the quantum yield of photosynthesis electron transfer in plants. When R:B of LED is1.5, the $\Phi_{\mathrm{PS} \text { II }}$ of leaves was higher than that of other light quality, but there was no significant difference between other treatments.

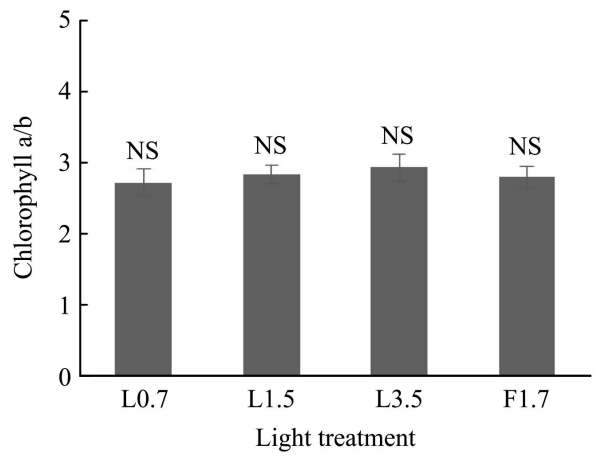

Note: Different letters in the same column indicate significant differences $(p<0.05)$ based on the Duncan's multiple range test. NS represent no significant difference at the $5 \%$ level.

Figure 4 Chlorophyll content and chlorophyll a/b of pepper seedlings grown under different lighting treatments

Table 1 Effects of light quality on photosynthetic characteristics of pepper seedlings

\begin{tabular}{|c|c|c|c|c|c|}
\hline Treatment & $\begin{array}{l}\text { Net photosynthetic rate } \\
\quad / \mu \mathrm{mol} \cdot \mathrm{m}^{-2} \cdot \mathrm{s}^{-1}\end{array}$ & $\begin{array}{l}\text { Stomatal conductance } \\
\qquad / \mathrm{mol} \cdot \mathrm{m}^{-2} \cdot \mathrm{s}^{-1}\end{array}$ & $\begin{array}{l}\text { Intercellular } \mathrm{CO}_{2} \text { concentration } \\
\qquad / \mu \mathrm{mol} \cdot \mathrm{mol}^{-1}\end{array}$ & $\begin{array}{l}\text { Transpiration rate } \\
/ \mathrm{mmol} \cdot \mathrm{m}^{-2} \cdot \mathrm{s}^{-1}\end{array}$ & $\begin{array}{c}\text { Instantaneous water } \\
\text { use efficiency }\end{array}$ \\
\hline L0.7 & $6.2 \pm 1.1 \mathrm{NS}$ & $0.104 \pm 0.045 b$ & $279 \pm 28 b$ & $0.87 \pm 0.32 \mathrm{c}$ & $7.6 \pm 1.6 \mathrm{a}$ \\
\hline L3.5 & $7.2 \pm 1.0 \mathrm{NS}$ & $0.157 \pm 0.075 \mathrm{ab}$ & $294 \pm 46 b$ & $1.26 \pm 0.31 \mathrm{~b}$ & $5.9 \pm 0.9 \mathrm{~b}$ \\
\hline F1.7 & $6.7 \pm 0.9 \mathrm{NS}$ & $0.213 \pm 0.063 \mathrm{a}$ & $330.2 \pm 18 \mathrm{a}$ & $1.40 \pm 0.34 \mathrm{ab}$ & $5.0 \pm 1.5 \mathrm{bc}$ \\
\hline
\end{tabular}

Note: Different letters in the same column indicate significant differences $(p<0.05)$ based on the Duncan's multiple range test. NS represent no significant difference at the $5 \%$ level.

Table 2 Effect of light quality on the chlorophyll fluorescence parameters of pepper seedlings

\begin{tabular}{|c|c|c|c|c|c|c|c|}
\hline \multirow{2}{*}{ Parameter } & \multicolumn{7}{|c|}{ Treatment } \\
\hline & $F_{\mathrm{v}} / F_{\mathrm{m}}$ & $F_{\mathrm{v}}{ }^{\prime} / F_{\mathrm{m}}{ }^{\prime}$ & $q_{\mathrm{P}}$ & $q_{\mathrm{N}}$ & $\Phi_{\mathrm{PS} \mathrm{II}}$ & ETR & NPQ \\
\hline L0.7 & $0.77 \pm 0.04 \mathrm{NS}$ & $0.5 \pm 0.07 \mathrm{NS}$ & $0.2 \pm 0.08 \mathrm{~b}$ & $0.77 \pm 0.03 \mathrm{NS}$ & $0.11 \pm 0.05 b$ & $53.06 \pm 25.12 \mathrm{NS}$ & $1.67 \pm 0.33 \mathrm{NS}$ \\
\hline $\mathrm{L} 1.5$ & $0.8 \pm 0.02 \mathrm{NS}$ & $0.51 \pm 0.03 \mathrm{NS}$ & $0.27 \pm 0.1 \mathrm{ab}$ & $0.76 \pm 0.04 \mathrm{NS}$ & $0.27 \pm 0.1 \mathrm{a}$ & $51.69 \pm 17.77 \mathrm{NS}$ & $1.61 \pm 0.27 \mathrm{NS}$ \\
\hline L3.5 & $0.79 \pm 0.03 \mathrm{NS}$ & $0.48 \pm 0.02 \mathrm{NS}$ & $0.24 \pm 0.06 \mathrm{ab}$ & $0.77 \pm 0.04 \mathrm{NS}$ & $0.12 \pm 0.03 b$ & $37.35 \pm 9.9 \mathrm{NS}$ & $1.64 \pm 0.33 \mathrm{NS}$ \\
\hline L1.7 & $0.8 \pm 0.01 \mathrm{NS}$ & $0.48 \pm 0.02 \mathrm{NS}$ & $0.33 \pm 0.09 \mathrm{a}$ & $0.79 \pm 0.02 \mathrm{NS}$ & $0.16 \pm 0.05 b$ & $54.16 \pm 15.86 \mathrm{NS}$ & $1.8 \pm 0.2 \mathrm{NS}$ \\
\hline
\end{tabular}

Note: Different letters in the same column indicate significant differences $(p<0.05)$ based on the Duncan's multiple range test. NS represent no significant difference at the $5 \%$ level.

In this study, we found that although the net photosynthetic rate under L3.5 had no significant difference with other treatments, it was in the maximum value, probably due to the lack of green light. Similarly, Yan et al. ${ }^{[31]}$ found that the net photosynthetic rate of peanut seedlings decreased under single green light (515-525 nm), probably due to the poor $\mathrm{CO}_{2}$ fixing ability of green light. Zhang et al. ${ }^{[32]}$ also found that green light led to a decrease in net photosynthetic rate of peach leaves. According to the research of Wang et al. ${ }^{[33]}$, under single green light, the Pn and $\mathrm{Fv} / \mathrm{Fm}$ of cucumber plants were lower than those under white light, which might be due to the different absorption rates of light at different wavelengths in plants. But it was also found that with the decrease of Pn, the transcription level of most genes which are involved in the Calvin cycle and the activity of Rubisco decreased. Similarly, previous studies by Matsuda et al. ${ }^{[34]}$ showed that plants under red plus blue light had higher photosynthetic rates, which were related to N, Rubisco content and cytochrome B6/F complex. Cao et al. ${ }^{[12]}$ found that the Fv/Fm, ФPSII and $\mathrm{q}_{\mathrm{p}}$ of cucumber seedlings under LED lamp with R:B of 2.3, 4 and 9 were greater than those under white or single light. Therefore, the increase of green light might reduce the net photosynthetic rate of leaves. However, Lee et al. ${ }^{[35]}$ found no difference in net photosynthetic rate, intercellular $\mathrm{CO}_{2}$ concentration, stomatal conductance and transpiration rate between Withania Somnifera L. under white fluorescent lamp and a spectral mixture of red and blue $(\mathrm{R}: \mathrm{B}=1)$, which might be due to low $\mathrm{R}: \mathrm{B}$ ratio.

\subsection{Energy consumption}

Different types of lamps had different energy use efficiency (Table 3). In the LED treatment with L1.5, the EUE and LUE were the highest, reaching 0.021 and 0.064 , and the total dry 
weight and lamp energy use efficiency (3.0) of pepper seedlings under L1.5 were also greater than those under other three light qualities. Compared with traditional fluorescent lamp, LED has lower energy consumption and more total dry weight with unit electric power, so in actual production, LED is more suitable for seedling production under artificial light.

Table 3 Accounts of energy efficiency of pepper transplants production under different light quality

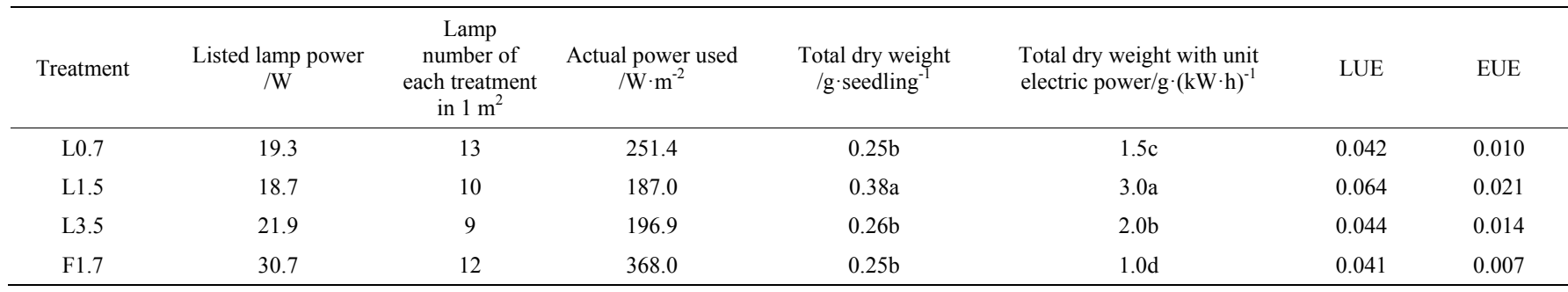

Note: Different letters in the same column indicate significant differences $(p<0.05)$ based on the Duncan's multiple range test. NS represent no significant difference at the $5 \%$ level.

\section{Conclusions}

Different light quality had significant effects on the growth and morphogenesis of pepper seedlings, while the biomass, chlorophyll content and photosynthetic capacity of plants grown under LED were similar or better than those under fluorescent lamps. The results showed that under the white LED with R:B of 1.5, the biomass and photosynthetic characteristics of pepper seedlings were the best. More high-quality pepper seedlings could be produced, with a total dry weight of $383.5 \mathrm{mg} /$ plant. Moreover, the energy consumption of LED was low, while its LUE and EUE could reach 0.064 and 0.021 , respectively, and more total dry weight could be produced under unit electric power, about three times as much as that under fluorescent lamp. Therefore, compared with traditional fluorescent lamps, the white LED light quality with $\mathrm{R}: \mathrm{B}$ ratio of 1.5 is suitable for pepper seedling production in plant factory..

\section{Acknowledgement}

This work was supported by the National Key Research and Development Program of China (2017YFB0403901).

\section{[References]}

[1] Chun C, Kozai T. A closed-type transplants production system. In: Molecular Breeding of Woody Plant. The Netherlands: Elsevier Science 2001; pp.375-384.

[2] Kozai T, Kubota C, Claim C, Afreen F, Ohyama K. Necessity and concept of the closed transplant production system. Transplant Production in the 21st Century, 2000; pp.3-19.

[3] Kozai T. Resource use efficiency of closed plant production system with artificial light: Concept, estimation and application to plant factory. Phys Biol Sci, 2013; 89(10): 1-15.

[4] Kozai T, Chun C. Closed systems using artificial light for producing quality transplants. In: The Korea-Japan Join Symposium on Transplant Production in Horticultural Plants, 1999; pp.53-60.

[5] Black C C, Brown R H, Moore R C. Plant photosynthesis. Basic Life Sciences, 1978; 30: 78-87.

[6] Clemens S. Plant physiology and function. Physiology and Function, 2017.

[7] Bourget C M. An introduction to light-emitting diodes. HortScience, 2008; 43(7): 1944-1946.

[8] Morrow, Robert C. LED Lighting in Horticulture. HortScience, 2008; 43(7): 1947-1950.

[9] Barta D J, Tennessen D J, Bula R J, Tibbitts T W. Wheat growth under a light source with and without blue photon supple mentation. ASGSB Bull, 1991; 5: 51.

[10] Brown C S, Schuerger A C, Sager J C. Growth and photomorphogenesis of pepper plants under red light-emitting diodes with supplemental blue or far-red lighting. Journal of the American Society for Horticultural
Science, 1995; 120(5): 808-813.

[11] Ricardo H, Eguchi T, Deveci M, Kubota C. Tomato seedling physiological responses under different percentages of blue and red photon flux ratios using LEDs and cool white fluorescent lamps. Scientia Horticulturae, 2016; 213: 270-280.

[12] Cao G, Zhang G, Yu J, Ma Y. Effects of different led light qualities on cucumber seedling growth and chlorophyll fluorescence parameters. Scientia Agricultura Sinica, 2013; 46(6): 1297-1304.

[13] Song J X, Meng Q W, Du W F, He D X. Effects of light quality on growth and development of cucumber seedlings in controlled environment. Int J Agric \& Biol Eng, 2017; 10(3): 312-318.

[14] Ohashi-Kaneko K, Takase M, Kon N, Fujiwara K, Kurata K. Effect of light quality on growth and vegetable quality in leaf lettuce, spinach and komatsuna. Environment Control in Biology, 2007; 45(3): 189-198.

[15] Arnon D. Copper enzymes in isolated chloroplasts, Phytophenoloxidase in Beta vulgaris. Plant Physiol., 1949; 24(1): 1-15.

[16] Polley H W. Implications of atmospheric and climatic change for crop yield and water use efficiency. Crop Sci., 2002; 42(1): 131-140.

[17] Javanmardi J , Emami S. Response of tomato and pepper transplants to light spectra provided by light emitting diodes. International Journal of Vegetable Science, 2013; 19(2): 138-149.

[18] Ricardo H, Chieri K. Physiological responses of cucumber seedlings under different blue and red photon flux ratios using LEDs. Environmental and Experimental Botany, 2015; 29(1): 66-74.

[19] Heo J, Lee C, Chakrabarty D, Paek K. Growth responses of marigold and salvia bedding plants as affected by monochromic or mixture radiation provided by a light-emitting diode (LED). Plant Growth Regulation, 2002; 38: 225-230.

[20] Ahmad M, Cashmore A R. Seeing blue: The discovery of cryptochrome. Plant Molecular Biology, 1996; 30(5): 851-861.

[21] Folta K M, Spalding E P. Unexpected roles for cryptochrome 2 and phototropin revealed by high-resolution analysis of blue light-mediated hypocotyl growth inhibition. The Plant Journal, 2001; 26(5): 471-478.

[22] Lin K H , Huang M Y , Huang W D, Hsu M H, Yang Z W, Yang C M. The effects of red, blue and white light-emitting diodes (LEDs) on growth, development and edible quality of hydroponically grown lettuce (Lactuca sativa L. var. capitata). Scientia Horticulturae, 2013; 150(2): 86-91.

[23] Staal M , Elzenga J T M , Elk A G V , Prins H B A, Volkenburgh E V. Red and blue light-stimulated proton efflux by epidermal leaf cells of the Argenteum mutant of Pisum sativum. Journal of Experimental Botany, 1994; 45(278): 1213-1218.

[24] Volkenburgh E V. Leaf expansion-an integrating plant behaviour. Plant Cell and Environment, 1999; 22(12): 1463-1473.

[25] Gomez C, Mitchell C A. Growth responses of tomato seedlings to different spectra of supplemental lighting. HortScience, 2015; 50: 112-118.

[26] Son K, Oh M, In B, Growth and bioactive compound synthesis in cultivated lettuce subject to light-quality changes. HortScience, 2017; 52(4): 584-591.

[27] Kim H. Green-light supplementation for enhanced lettuce growth under red- and blue-light-emitting diodes. HortScience, 2004; 39(7): 1617.

[28] Borowski E, Michałek S, Rubinowska K, Hawrylak-Nowak B, Grudzinski W. The effects of light quality on photosynthetic parameters and yield of lettuce plants. Acta Scientiarum Polonorum, 2015; 14(5): 177-188.

[29] Craver J K, Gerovac J R, Lopez R G. Light intensity and light quality from sole-source light-emitting diodes impact phytochemical 
concentrations within Brassica Microgreens. J. Amer. Soc. Hort. Sci, 2017; 142(1): 3-12.

[30] Kopsell D A, Sams C E, Barickman T C. Sprouting broccoli accumulate higher concentrations of nutritionally important metabolites under narrow-band light-emitting diode lighting. Horticultural Science, 2014; 139 469-477.

[31] Yan M, Wang M, Wang H, Wang Y, Zhao C. Effects of light quality on photosynthetic pigment contents and photosynthetic characteristics of peanut seedling leaves. Chinese Journal of Applied Ecology, 2014; 25(2): 483. (in Chinese)

[32] Zhang B B, Xu J L, Zhou M, Yan D H, Ma R J. Effect of light quality on leaf photosynthetic characteristics and fruit quality of peach (Prunus persica L. Batch). Photosynthetica, 2018; 56(4): 1113-1122.

[33] Wang H, Gu M, Cui J, Shi K, Zhou Y, Yu J. Effects of light quality on $\mathrm{CO}_{2}$ assimilation, chlorophyll-fluorescence quenching, expression of Calvin cycle genes and carbohydrate accumulation in Cucumis sativus. Journal of Photochemistry \& Photobiology B Biology, 2009; 96(1): 30-37.

[34] Matsuda R. Photosynthetic characteristics of rice leaves grown under red light with or without supplemental blue light. Plant and Cell Physiology, 2004; 45(12): 1870-1874.

[35] Lee S H, Tewari R K, Hahn E J, Paek K. Photon flux density and light quality induce changes in growth, stomatal development, photosynthesis and transpiration of Withania Somnifera (L.) Dunal. plantlets. Plant Cell Tissue and Organ Culture, 2007; 90(2): 141-151. 